\title{
EL PAISAJE
}

\section{AMAZÓNICO 1}

Por José Antonio Dorado Zúñiga 2 Profesor titular Escuela de Comunicación Social Facultad de Artes Integradas Universidad del Valle adorado@calypso.com.co

RESUMEN:

Me interesa reflexionar en torno a las representaciones del paisaje, interpretando por paisaje un concepto amplio que desborda el límite de la visión común donde la naturaleza es protagonista. Entendiendo a su vez que la naturaleza tiene en sus componentes centrales a los seres vivos, seres como hombres, animales, insectos y plantas. Somos parte de un paisaje humano y no podemos excluirnos, sin pretender con esto caer en banalismos homocéntricos.

PALABRAS CLAVE:

Amazonas, mágico, inmensidad, representación, paisaje, yagé, ayahuasca, contaminación, inseguridad. 
Apartes de una crónica de viaje a la última selva colombiana

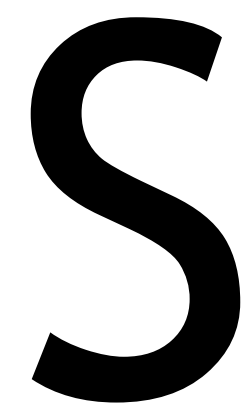

Sobrevolando el tema

Navegábamos en medio de asombrosos gigantes de agua, con legiones de ángeles y demonios a sus espaldas. Debajo de ellos y a lo lejos se observaba pedazos de la cordillera, que albergan entre sus lomos pequeños grupos de bosques y un río que incesante lucha por regar sus aguas. Me acerqué más al cristal buscando esquivar el reflejo en la ventanilla del avión, mientras Diego Garcés busca el ángulo apropiado para lograr una buena foto. Siempre me ha parecido mágico el acto de estar sentado en una nave inmensa sobrevolando las alturas. Es una vivencia muy reciente y es asumida por obvia. Quizás por eso me llama la atención, lo obvio nunca me parece tan simple. Es el sueño de Ícaro vuelto realidad. Nuestros ojos están tan acostumbrados a las imágenes aéreas que parece que hubiéramos nacido con la posibilidad del vuelo, pero esta opción apenas tiene un poco más de un siglo.

Lo importante de estar en vuelo no es solo el hecho de levitar, sino mirar desde las alturas. La emoción y el sentimiento de la levitación se magnífica con la mirada y un punto de vista. Es la mirada cenital, un punto de vista que en los escritos bíblicos solo se les había concedido a los dioses. La instalación de esa nueva mirada nació casi paralela con el cinematógrafo y la locomotora y, cambió para siempre los modos de registrar el mundo. Ahora los artefactos mecánicos son mediadores de nuestros modos de ver, de vernos y de representarnos, no solo a nosotros sino al paisaje del cual inevitablemente hacemos parte.

Hacía media hora habíamos salido de Villavicencio y ahora dejábamos atrás los últimos riscos de la cordillera oriental, que forma el escudo guyanés, y nos internamos en la extensa llanura amazónica, un hermoso mar verde casi infinito a nuestros ojos, ese verde selva de muchos colores que pocos conocen y que corresponde a la tercera parte del territorio colombiano. Como estábamos en el mes de febrero, presumía, por lasaveriguaciones que había hecho, que estaríamos en verano, sin embargo yo que vivo en Colombia, sé que hay que tener un plan $\mathrm{B}$, porque en el trópico el tiempo es impredecible y más en los últimos tiempos.

Al acercarnos a nuestro destino se hace evidente la presencia del Río Vaupés, a su alrededor son visibles las incursiones de colonos, hay muchas quemas, y una pequeña ciudad improvisada alrededor del aeropuerto. Las llantas del avión parecen tocar peligrosamente algunas casas del pueblo y finalmente aterriza en la pista.

\section{La aterrizada}

Al llegar nos enteramos de que no estamos en un aeropuerto cualquiera. Hay soldados del ejército custodiando directamente la entrada a la selva, nos pidieron mostrar nuestros documentos y quedó reseñada nuestra entrada el 17 de febrero de 2007 a las diez de la mañana. El aeropuerto Alberto León Bentley es la vía más importante de acceso. Un viejo avión de carga Varig DC10 que, debido a su poder de contaminación e inseguridad tiene prohibido su aterrizaje en los principales terminales aéreos del mundo, campea con tranquilidad en la pista. Dicen que ha traído más de doscientas motos. Aquí la cultura 
occidental ha entrado por avión y por satélites. Como a los indígenas se los ha visto incapaces de gobernar, e históricamente se han despreciado sus conocimientos por parte de los gobiernos centrales, la gente que tiene el poder en los cargos públicos es gente del interior. Son ellos los que han traído las costumbres y necesidades occidentales. Y como la selva no produce motos, ni cemento, los que tienen el poder y piensan que esos elementos son símbolos de progreso, los deben traer del centro del país. Los pocos carros que existen los trajeron en los aviones Hércules del ejército.

Como la gente del interior es la que tiene los mejores salarios, las mejores propiedades y el manejo de la economía de la región, traen muchos alimentos por avión. Después de pasar el cerco militar, recogimos el equipaje buscando ir a la plaza central. Un enjambre de hombres en motos nos ofrece sus servicios de transporte a 500 pesos por persona y en pocos minutos estamos frente a la iglesia del parque central. En la plaza era inevitable recordar las descripciones de algunos autores que había leído. En primera instancia recordé el texto de Jean E. Jackson:

Cuando llegué al Vaupés en noviembre de 1968, encontré que el pueblo de Mitú consistía de unos 700 habitantes, la mayoría de ellos de otras partes del país y anhelando regresar, enviados allí para atender, directa o indirectamente, las necesidades percibidas de la población indígena de habla tucano y arawak. La pista aérea era un río de lodo y el pueblo parecía sacado de una película del Salvaje Oeste. Mi compañero de viaje, Peter Silverwood-Cope, quien estaba haciendo trabajo de campo entre los Makú colombianos, me dijo, "Esta es la parte más triste del viaje". ${ }^{3}$

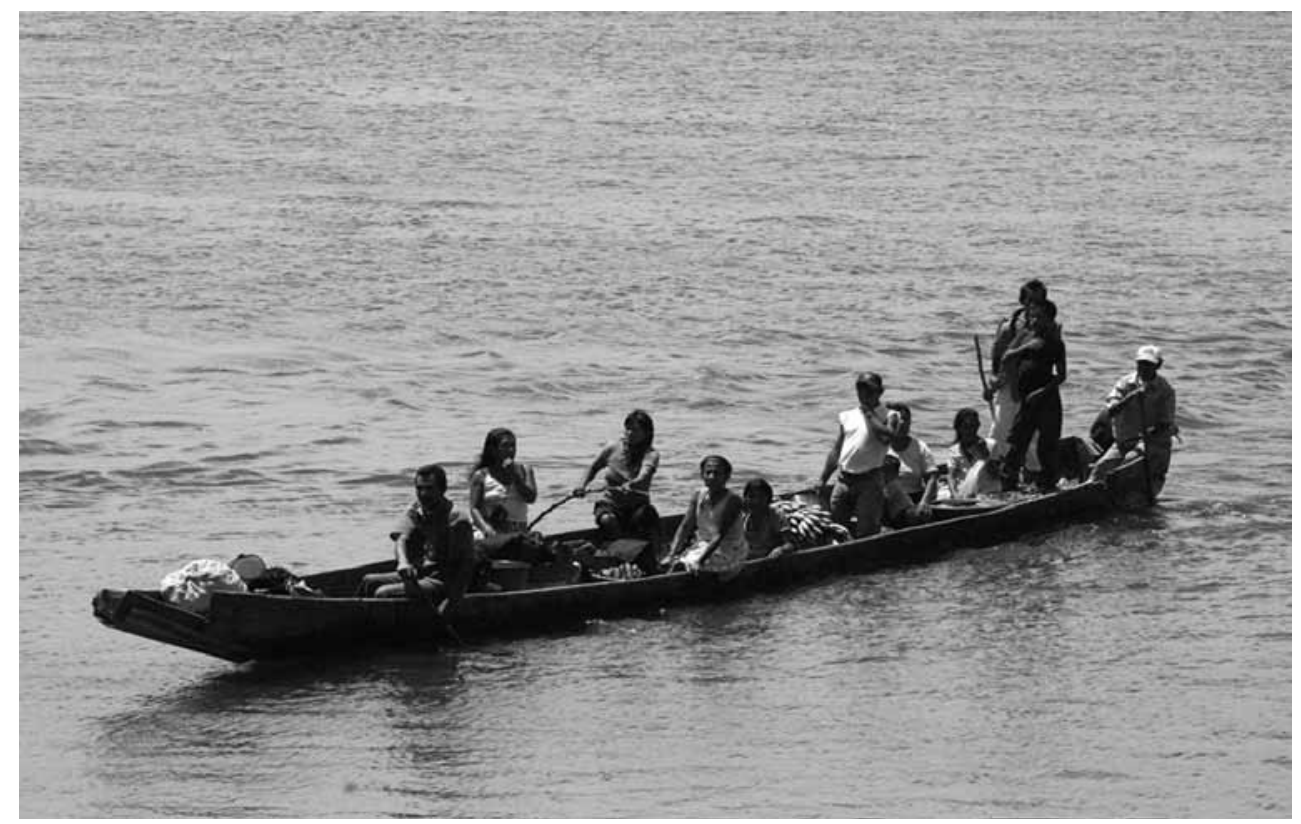

\section{También recordé la poética descripción que hace Wade Davis en su libro El río:}

No se había asentado aún el polvo en la pista de aterrizaje, cuando me di cuenta de que Mitú era distinta a cualquier otra población que hubiera visto en la Amazonía. Aunque pasaba por ser la capital de una región tan grande como Irlanda, el adormilado pueblito estaba compuesto de una calle única que iba desde la pista de aterrizaje hasta la ribera del Vaupés. A lo largo había callejuelas limpias de gravilla, cabañas recién pintadas y docenas de niños en uniformes claros, que reían y jugaban junto a la iglesia. Era lo más cercano a lo idílico que había visto en todo el Amazonas ${ }^{4}$. 
Debo confesar que este viaje estuvo motivado por la lectura de ese libro, es decir que primero lo imaginé, creando mis imágenes que proyectaban las palabras, así construí un paisaje imaginario, que le daba un asombroso sentido a la selva que habían construido mis referentes mediáticos. Ahora que estaba allí, ese pueblo idílico tenía la apariencia de estar brutalmente transformado, al punto de que el propio Davis, cuando le enseñé las imágenes en Washington en el año 2007, tuvo la misma impresión.

Me interesa reflexionar en torno a las representaciones del paisaje, interpretando por paisaje un concepto amplio que desborda el límite de la visión común donde la naturaleza es protagonista. Entendiendo a su vez que la naturaleza tiene en sus componentes centrales a los seres vivos, seres como hombres, animales, insectos y plantas. Somos parte de un paisaje humano y no podemos excluirnos, sin pretender con esto caer en banalismos homocéntricos. Desde esta perspectiva me interesa describir espacios significativos de las comunidades que vamos a visitar, enfatizando el enfoque cultural, como un elemento vital en la comprensión de los elementos que interactúan, porque nos permite actualizar su re-significación a partir de una mirada holística atravesada por aspectos históricos, filosóficos y estéticos. No pretendo ostentar una visión de especialista, mi anhelo es muy sencillo y complejo en sí mismo. Aspiro a transmitir la mirada de un buen observador, respetuoso y dignamente informado. Voy a trabajar con frecuencia las referencias de las representaciones explícitas e implícitas del paisaje, entendiendo por las primeras aquellas que parten de materiales fotográficos, cinematográficos y pictóricos, y por las implícitas los comportamientos que a través de la observación requiera consignar.

\section{Representaciones estéticas del Amazonas}

Los viajes o exploraciones al Amazonas tienen consciente e inconscientemente referencias con fabulosos textos. La imaginación del hombre occidental se transformó cuando Homero narró las andanzas y desventuras de su héroe Ulises, desde entonces los viajes se convierten en un territorio mágico donde todo puede ocurrir.

Cuando occidente conoce el nuevo mundo, su visión se transforma y siembra una mirada que va a marcar el sentido y hasta el destino de las selvas en el nuevo continente. Gabriel García Márquez,

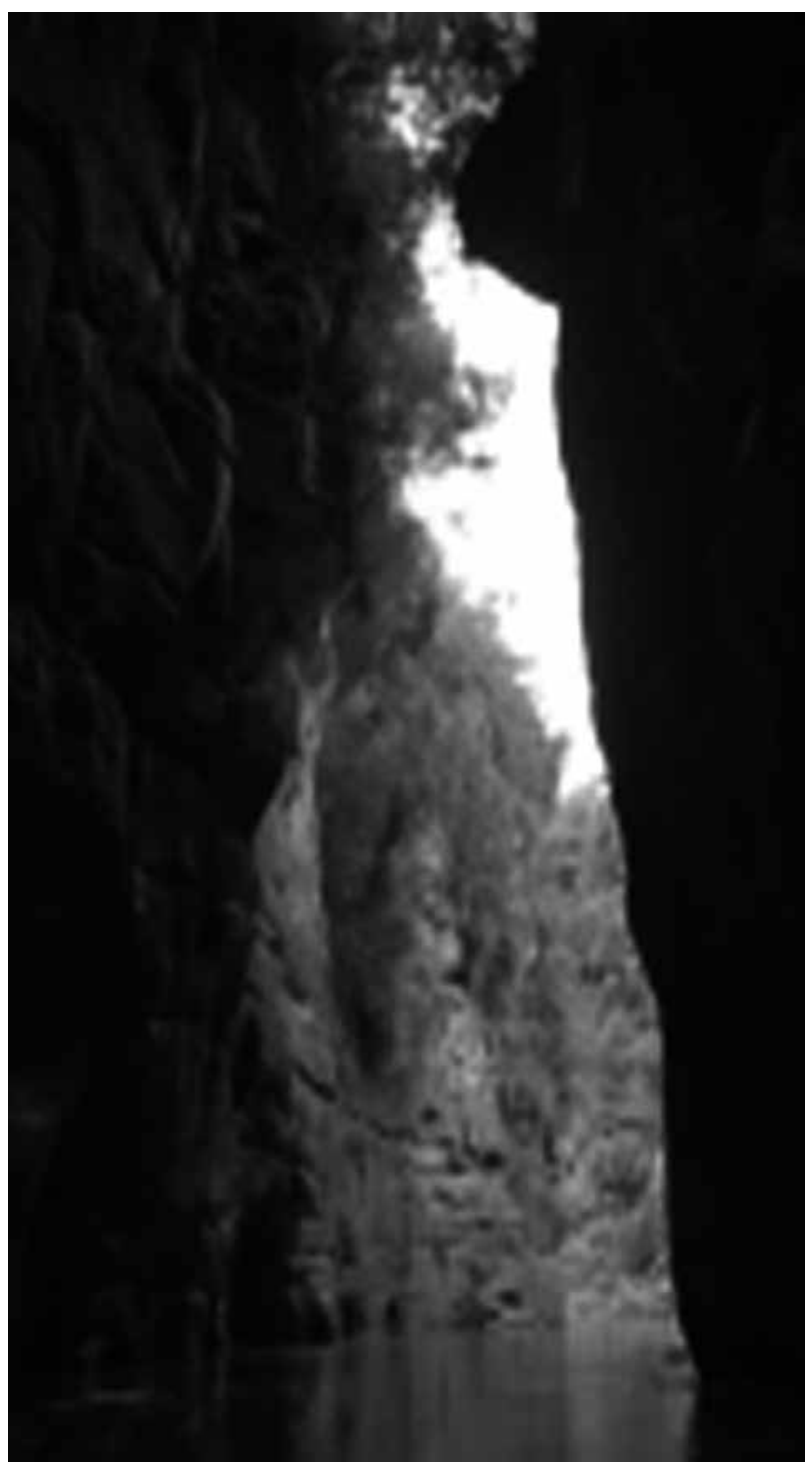

al recibir el Premio Nobel de literatura, evocó al inicio de su discurso La Soledad de América Latina, la crónica de Antonio Pigafetta, el navegante florentino que acompañó a Magallanes, en su primer viaje alrededor del mundo, a su paso por América Meridional:

Contó que había visto cerdos con el ombligo en el lomo, y unos pájaros sin patas cuyas hembras empollaban en las espaldas del macho, y otros como alcatraces sin lengua cuyos picos parecían una cuchara. Contó que había visto un engendro animal con cabeza y orejas de mula, cuerpo de camello, patas de ciervo y relincho de caballo. Contó que al primer nativo que encontraron en la Patagonia le pusieron enfrente un espejo, y que aquel gigante enardecido perdió el uso de la razón por el pavor de su propia imagen ${ }^{5}$. 
Tal como lo advierte García Márquez, en esas representaciones se vislumbran los gérmenes de las futuras representaciones estéticas, en el campo literario y en general en las artes. A la crónica de Pigafetta le sobrevienen los periodos de conquista de territorios a manos de españoles, ingleses, alemanes y portugueses. Sus miradas occidentales tejen otros mitos exógenos, así lo precisa el discurso del Nobel:

Los cronistas de Indias nos legaron otros incontables. El dorado, nuestro país ilusorio tan codiciado, figuró en mapas numerosos durante largos años, cambiando de lugar y de forma según la fantasía de los cartógrafos. En busca de la fuente de la Eterna Juventud, el mítico Alvar Núñez Cabeza de Vaca exploró durante ocho años el norte de México, en una expedición venática cuyos miembros se comieron unos a otros, y solo llegaron cinco de los 600 que la emprendieron. Uno de los tantos misterios que nunca fueron descifrados, es el de las once mil mulas cargadas con cien libras de oro cada una, que un día salieron del Cuzco para pagar el rescate de Atahualpa y nunca llegaron a su destino. Más tarde, durante la colonia, se vendían en Cartagena de Indias unas gallinas criadas en tierras de aluvión, en cuyas mollejas se encontraban piedrecitas de oro. Este delirio áureo de nuestros fundadores nos persiguió hasta hace poco tiempo. Apenas en el siglo pasado la misión alemana encargada de estudiar la construcción de un ferrocarril interoceánico en el istmo de Panamá, concluyó que el proyecto era viable con la condición de que los rieles no se hicieran de hierro, que era un metal escaso en la región, sino que se hicieran de oro $^{6}$.

En la copiosa publicación de los textos de Alexander Von Humboldt, aparecen los primeros registros sobre aspectos del paisaje, la distribución de las especies vegetales en la geografía del continente, distribución de las comunidades indígenas, discusiones históricas sobre los descubrimientos, crónicas de los viajes e incluso reflexiones acerca de la realidad política de algunos sitios visitados.

Paralelo a las investigaciones de Von Humboldt, el mundo occidental conoce el caucho, su importancia económica va a tener una gran trascendencia en las transformaciones sociales y culturales de la selva, donde los colonos explotan estas tierras, creando condiciones mercantiles que no tenían antecedentes en América.

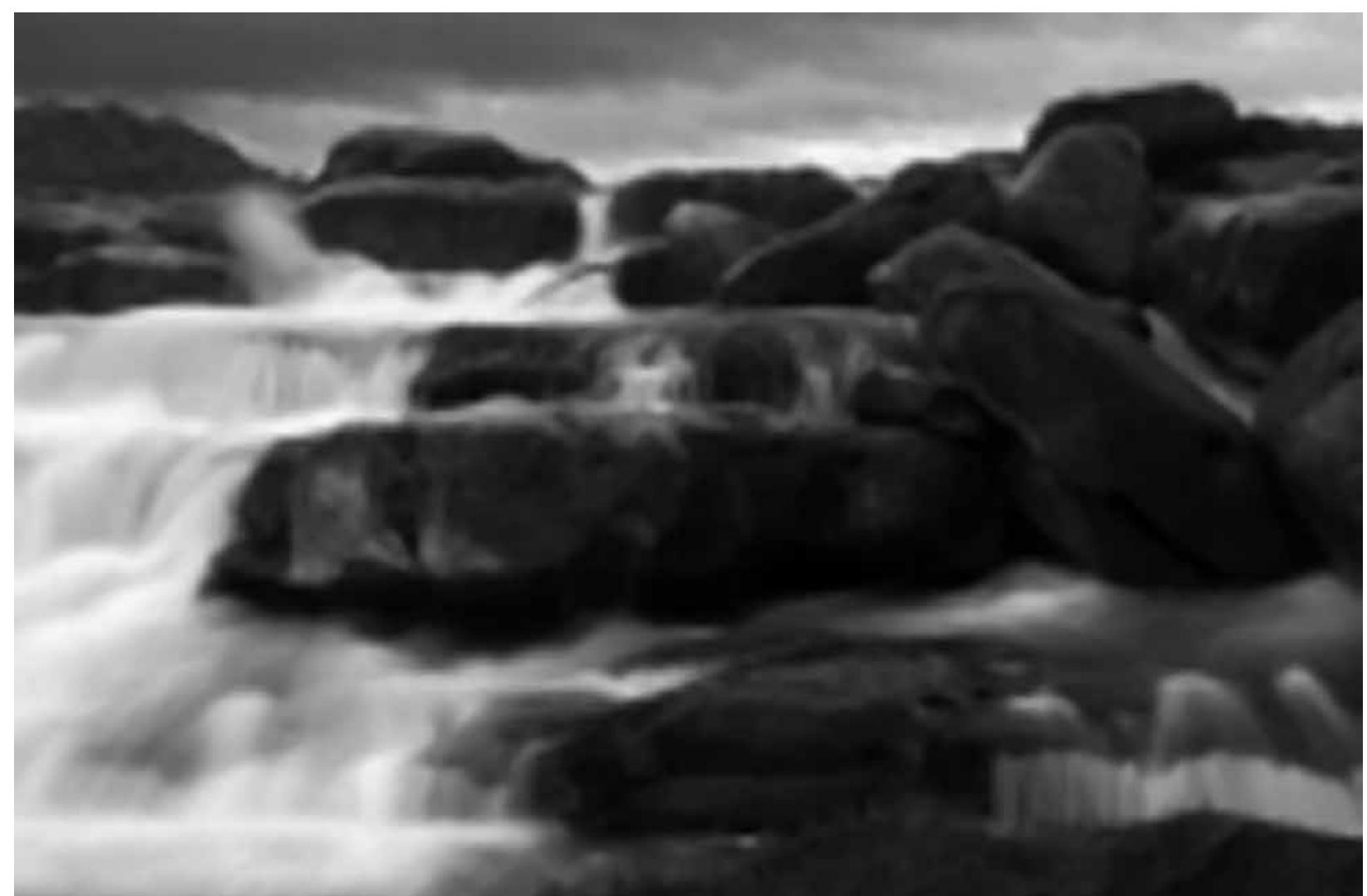




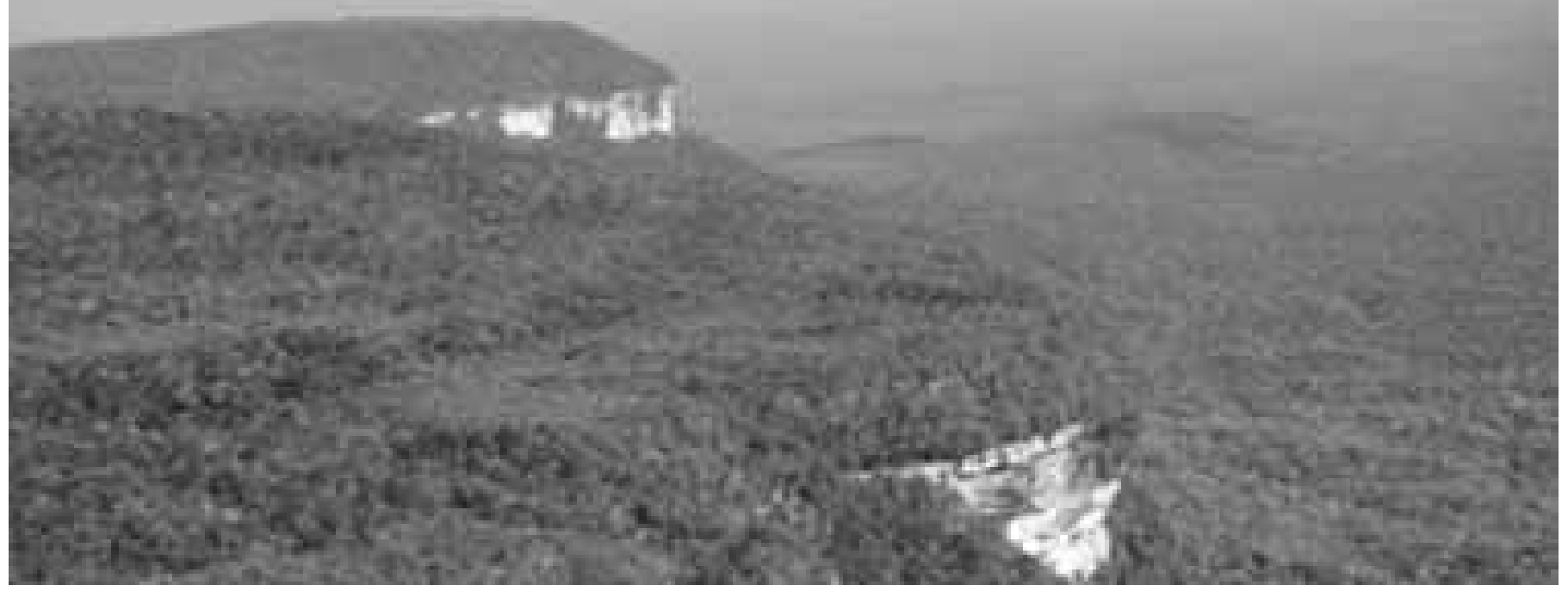

En el contexto de las colonias, las experiencias de viajeros se desplazan por diferentes lugares del mundo. Entre ellos, el escritor polaco Joseph Conrad desde joven se embarca en diversas expediciones marinas en la flota mercante francesa y vive aventuras que lo involucraron en tráfico de armas y conspiraciones políticas que llegan hasta el Caribe venezolano. Años después visitará Bombay y otros lugares del sudeste asiático que alimentarán su visión de los complejos paisajes de ultramar. En 1889 cumple el sueño de conocer África. Al llegar al Congo conoció las atrocidades que cometían los colonos contra la población nativa, dando lugar a los paisajes oscuros que le inspiraron El corazón de las tinieblas.

A comienzos del siglo XX, con el vertiginoso avance tecnológico cuando aparece el avión, el ferrocarril, el cine, el fonógrafo y el telégrafo, los viajeros exploran los hallazgos de nuevas plantas de usos medicinales e industriales, tomando la selva Amazónica como despensa para los nuevos desafíos científicos y mercantiles. Con el auge del carro, se dispara la implementación de plantaciones de caucho. Es la época de la creación de Fordlandia, un gigantesco dispositivo de explotación cauchera, que terminó siendo fracaso del imperio de Ford, que pretendía crear una ciudadela en la selva, para abastecer de llantas las grandes demandas de un mundo industrial que vertiginosamente empezaba a cambiar el caballo por el automóvil.

En este contexto, los gobiernos colombianos de turno no demuestran tener visión ni capacidad de reacción frente a los nuevos escenarios y empiezan a ceder territorios selváticos en sus fronteras. Es cierto que buena parte de los hechos ocurridos estuvieron relacionados con intereses y presiones extranjeras, que manipularon y aprovecharon las contradicciones internas, pero también es cierto que las personalidades que manejaban los destinos del país no tenían perspectivas ni políticas claras para establecer acuerdos jurídicos convenientes; un caso patético corresponde a la última cesión de territorios que el gobierno colombiano del presidente Laureano García Ortíz, por medio de un tratado de límites y navegación con los Estados Unidos del Brasil, a cambio de tener un derecho internacional para que los barcos de nacionalidad colombiana pudieran navegar libremente por el Amazonas ${ }^{7}$, tiempo después un acuerdo internacional declararía que la navegación por el río Amazonas es libre para las embarcaciones de cualquier nacionalidad.

El primer golpe en la cesión de terrenos selváticos colombianos ocurrió con la independencia de Panamá, donde no solo se cede el territorio privilegiado para crear la conexión interoceánica, sino también las selvas de Urabá. En 1922 se celebró el tratado de fronteras SalomónLozano entre Colombia, Perú y Brasil, pero solo en 1930 los peruanos se retiraron al sur del 
río Putumayo y se fundó la Comisaría Especial del Amazonas.

El conflicto por el establecimiento de linderos fronterizos va a propiciar condiciones para que ocurra una transformación estética particular del paisaje en América latina. Uno de los hombres enviados por el gobierno colombiano para fijar los límites con Venezuela es el abogado y escritor José Eustasio Rivera, quien (tal como Conrad) al llegar al Amazonas se entera de las atrocidades cometidas a los indígenas a manos de los caucheros. Se sabe que en esta experiencia contrajo el beri-beri, fue amenazado por la fiebre y el tormento de la fiebre tropical. De esta experiencia surge La Vorágine (1924), una novela narrada en primera persona, que proyecta la teoría determinista, recrea el infierno verde y la épica del hombre contra la naturaleza, donde las fuerzas cósmicas o infernales acosan al hombre hasta devorarlo. Esta obra va a ser muy importante, por ser una de las primeras representaciones del Amazonas en la perspectiva del infierno verde, que va a influenciar la creación de las novelas de la selva latinoamericana, entre ellas Canaima, del escritor venezolano Rómulo Gallegos y Calunga del brasileño Jorge de Lima.

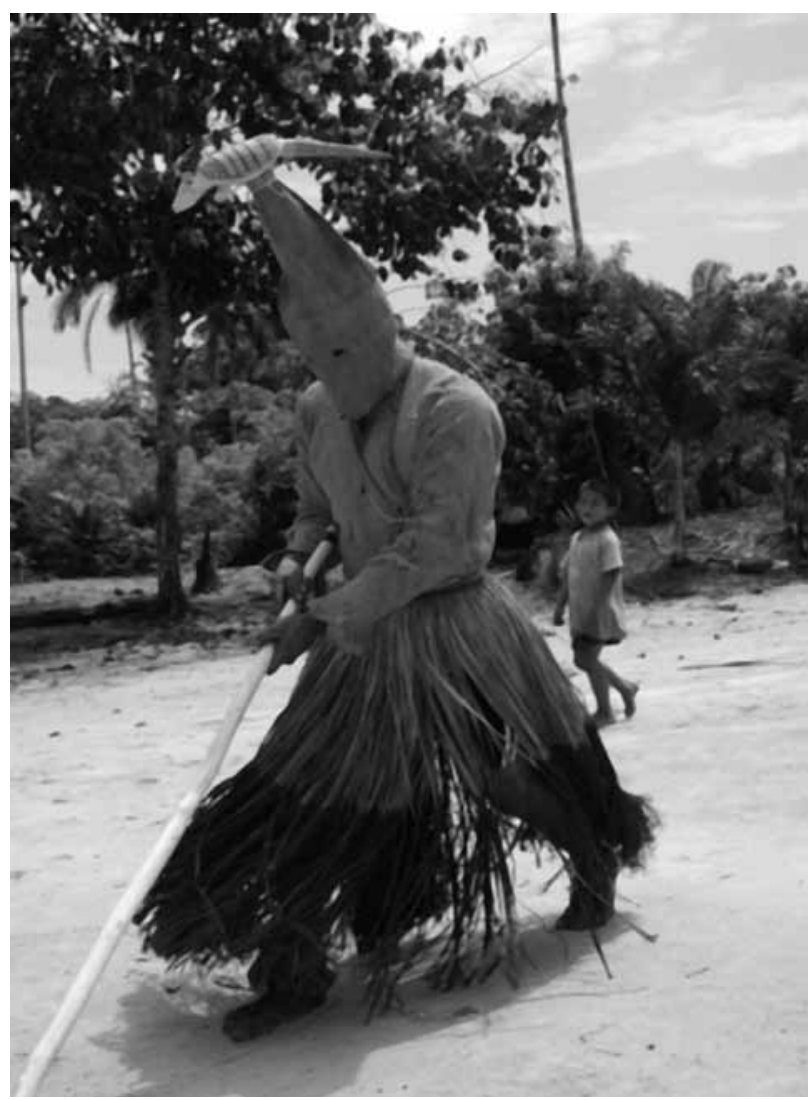

Un aspecto determinante en La Vorágine es que los hechos que se narran están inspirados en un contexto realista, de sucesos ocurridos en las tierras aledañas al río Caquetá, en los límites con Ecuador y Perú, donde el auge de los precios del caucho en el Brasil despierta la ambición de los caucheros, dando lugar a la inicua explotación de los indígenas y mestizos que son esclavizados bajo horrorosas condiciones. Rivera se entera de estos hechos, pero la selva que él conoce es en los límites con Venezuela y, en consecuencia, en su obra hace un traslape geográfico y lo ubica en las selvas del Vaupés, que para entonces son prácticamente impenetrables, tanto por vía aérea como por los ríos. En consecuencia no solo se altera el contexto geográfico sino el aspecto cultural, pues no conocía los cubeos, los tanimukas, los kawiyarí y tantas comunidades del nordeste amazónico, hasta ese entonces no descubiertas ${ }^{8}$.

Schultes regresó a su río amado, el Apaporis, en 1953, e inició la fase más productiva de toda su carrera como etnobotánico. Esta vez contó con el apoyo de Miguel Dumit, un empresario antioqueño que compró una avioneta con el propósito de establecer en las selvas un puesto comercial, para extraer caucho. Dumit contrató a Schultes, quien vio en este trabajo una oportunidad extraordinaria para sus descubrimientos.

El 25 de enero de 1953, el joven escritor William Burroughs, estudiante de Harvard, que había emprendido su viaje por Suramérica, llegó a Bogotá, justo cuando el profesor Richard Evans Schultes se disponía a viajar a Boston. Burroughs le trasmitió su decidido interés de emprender el viaje para probar Yagé o Ayahuasca, una de las plantas psicotrópicas más importantes del Amazonas, que él nunca había experimentado. El profesor que había vivido la experiencia con diversos chamanes, le ofreció sus contactos para que viajara al Putumayo a cumplir su misión.

Burroughs, en su productiva visita por Sudamérica, consignó el registro de sus andanzas y experiencias en las cartas que le escribió a Allen Ginsberg, recopiladas en el libro Cartas del Yagé (o Cartas de (a Ayahuasca) publicado por Anagrama. Siete años después, Ginsberg haría lo mismo. Estas correspondencias dan cuenta de una aproximación biográfica y las miradas literarias y místicas sobre los entornos políticos y sociológicos de los países que visitaron. El texto indaga las manifestaciones físicas y psicológicas que le provocaron el consumo 
del psicotrópico, pero también emplea el poder del diario para hacer manifiesta su mirada de lo norteamericano sobre lo sudamericano, sobre los comportamientos y en algunos casos sobre las descripciones de sus paisajes, que incluyen sus comentarios, obsesiones y malestares.

Burroughs traza una ruta iniciadora por Suramérica que se hará frecuente en los años sesenta, donde el Amazonas colombiano será visitado no solo por antropólogos, sociólogos y gente del común, en el periodo de la psicodelia, donde nuevamente el profesor Richard Evans Schultes será uno de los grandes iniciadores, no solo por el entusiasmo que trasmitía a sus estudiantes en Harvard sino por la amplia divulgación que empiezan a tener sus publicaciones.

Entre ellas se destaca El Bejuco del Alma que escribió con Robert F. Raffauf. Los autores revelan el maravilloso mundo de las comunidades amazónicas donde los médicos tradicionales hacen curaciones con plantas medicinales y donde la magia y los rituales no solo hacen parte de su cosmogonía sino que están íntimamente ligadas a sus prácticas cotidianas. 


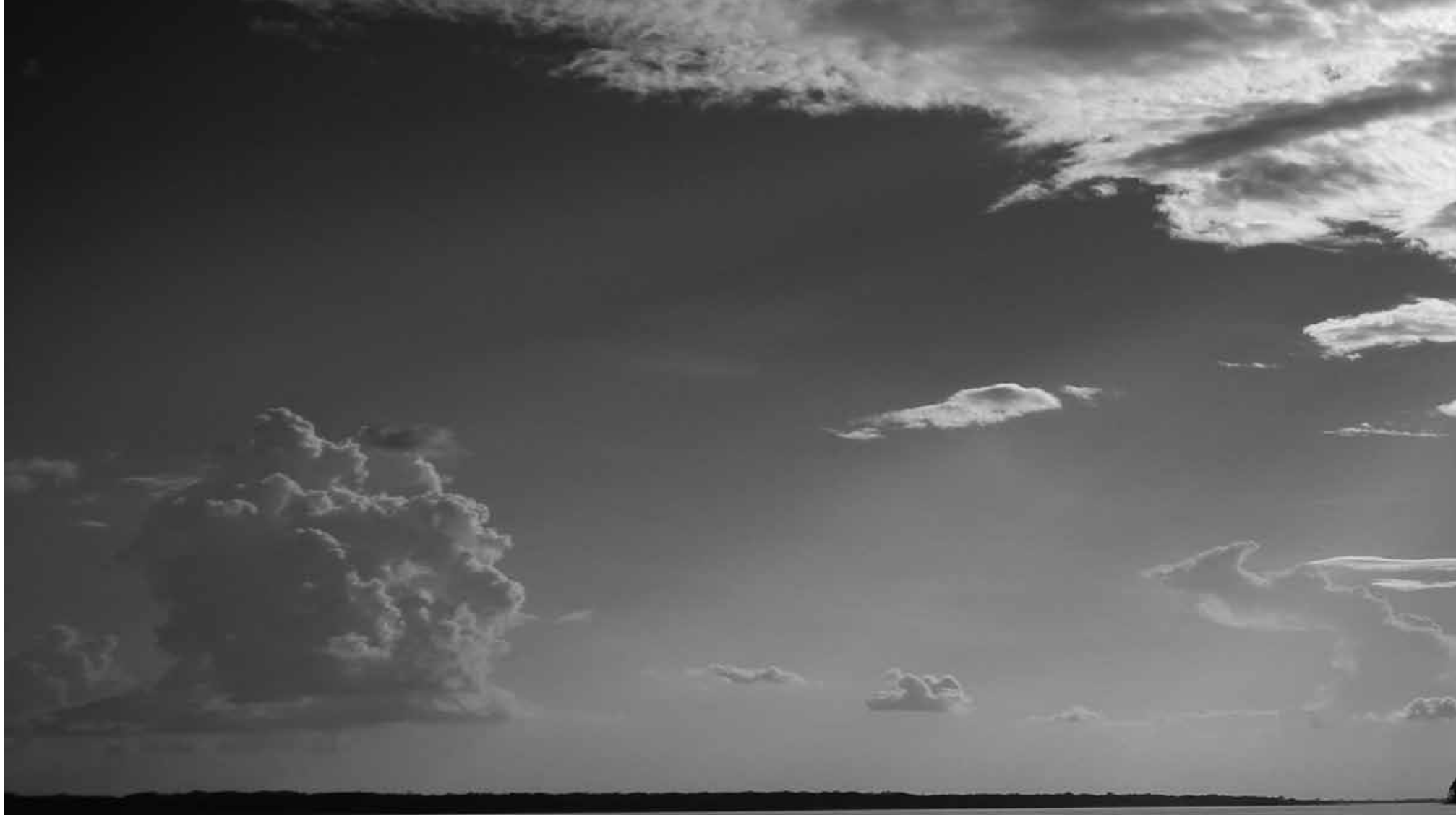

Un aspecto particular son las fotografías tomadas por el profesor Schultes, a través de las cuales se proyecta su significado implícito, pues habitualmente los encuadres fotográficos que hicieron los europeos y norteamericanos que visitaron el Amazonas eran tomados a la altura de los ojos de los blancos. Esto determinaba que los registros se hicieran en picada, en razón a que la altura de los foráneos sobrepasaba la altura de los nativos y por tanto en los registros frecuentemente reproducen la visión de una mirada que aplasta, que minimiza y trasmite sus puntos de vista. En este orden de ideas, las fotografías tomadas por el profesor no solo son maravillosas por sus encuadres, sino por el respeto con que implícitamente se aproximaba a los Chamanes. En muchos casos se arrodillaba, literalmente ante ellos, para conseguir encuadres en contrapicada que magnificaban el valor del personaje retratado, porque él con su investidura intelectual de tener un doctorado en los años cuarenta, sabía que los grandes maestros de las plantas no estaban en Harvard sino en el Amazonas 9.
La escritura del libro El Bejuco del Alma la inició Schultes cuando se retiró del cargo de director del Museo Botánico de la Universidad de Harvard. En principio era una extensión de su texto Where the Gods Reign, pero en el proceso de re-escritura adquirió vida propia. Algunas de las notas de pie de página de las fotografías fueron elaboradas por su amigo Reichel Dolmatoff, a quien está dedicada la publicación.

En cuanto a las representaciones estéticas, en los años setenta se reactiva el tema de la conquista con una perspectiva realista, que busca la fuerza documental de los paisajes para trasmitir el impacto emocional que no pueden transmitir los estudios científicos, así aparece en el cine Aguirre y la Ira de Dios, donde se actualiza el tema de los imaginarios europeos, que enceguecidos por la ambición y la búsqueda del oro, terminan en la demencia atrapados por la desesperanza en la selva. A este film le seguirán otros films de Herzog como Fitzcarraldo y Cobra Verde, que incluye escenas que fueron filmadas en Colombia. En esta misma perspectiva de reconstrucciones históricas 
a fines de los años ochenta se filma La Misión protagonizada por Robert de Niro, en la cual también se recrean secuencias en Colombia, donde incluso se toma una comunidad de los indígenas emberá y se trasladan a la costa atlántica, aplicando las logísticas mediáticas de Hollywood, donde priman la impresiones pintorescas de los indígenas, sin tener mayores reparos en el respeto por los entornos paisajísticos y culturales evocados. En el contexto mediático colombiano el audiovisual, en general, no ha explorado la selva como un recurso expresivo.

En los años setenta aparecieron algunas películas donde se ridiculizaba la condición del indígena, o se aprovechan los registros de nativos, utilizando la licencia cultural que existe en occidente donde las mujeres indígenas son como una especie de animales salvajes que no requieren cubrir sus pezones, o que algunos ritos pueden ser tratados fuera de contexto, tal como ocurrió con la película Holocausto Caníbal.

En el caso de la televisión, ha retomado en dos ocasiones la adaptación de La Vorágine. En su primera versión de los años setenta fue una telenovela de estudio que tuvo un gran impacto en el público, pero sin mayor trascendencia estética. Posteriormente aparece la versión dirigida por Lisandro Duque, que recrea varias secuencias en el contexto paisajístico del Amazonas. Así mismo se hizo la adaptación de la novela Mi alma se la dejo al diablo, escrita por Germán Castro Caicedo, sin mayores consecuencias de una propuesta estética interesante. La única excepción ha sido el trabajo documental, que se realizó en el espacio de Yurupary, donde se filmaron registros de diferentes comunidades del país, entre ellas de varias regiones amazónicas, incluido el Vaupés. Estos materiales fueron filmados en super 16 milímetros y constituyen un importante documento y patrimonio cultural del país. De igual manera hay varios trabajos de antropólogos y documentalistas, nacionales y extranjeros, que han hecho trabajos importantes. El más destacado y reconocido es Los Nukak, que justamente fue filmado en el nordeste amazónico, haciendo un seguimiento a una de las últimas comunidades nómadas, que se encuentra en extinción.

Durante mucho tiempo la selva ha estado marginada de representaciones estéticas, o al menos no ha estado en boga. Hay antecedentes notables en la pintura, como algunas obras de Gonzalo Ariza,
María Teresa Negreiros (brasilera radicada en Cali) y muchos otros talentosos artistas, que han coincidido en sus búsquedas de la representación del paisaje amazónico, pero no ha sido el lugar común de la expresión artística nacional. No obstante los desarrollos que las artes han tenido, en medio de todos los obstáculos del subdesarrollo, es oportuno afirmar que el nordeste amazónico no ha sido un tema prioritario o frecuente en las prácticas artísticas de los autores colombianos, lo cual también es significativo, porque territorios como el Vaupés y Ríos como el Cananarí o el Apaporis son completamente desconocidos, no solo por los artistas sino por la gran mayoría de colombianos.

Entre los casos más visibles, algunas excepciones las encontramos en las artes plásticas con los trabajos de Alberto Baraya, quien ha explorado en torno a las expediciones, la botánica y el exotismo, o los trabajos de Nadin Ospina, quien durante un periodo de 15 años retomó la iconografía procedente de las fatorias de Disney, Matt Groening y Hergé (Mickey Mouse, Tin-Tin, los Simpson) para convertirlos en piezas de cerámica prehispánica, representando las paradójicas formas de colonialismo cultural. En la pintura son varios los autores que han explorado el Amazonas, sin embargo es Carlos Jacanamijoy, hijo de un chamán reconocido y miembro de la comunidad Inga del Putumayo, el autor más importante en las representaciones artísticas del entorno amazónico, cuya obra se exhibe en el Museo Smithsonian de Washington.

Hoy encontramos diversas tendencias desde las artes tradicionales donde la literatura, la música, la pintura, la escultura, el cine y las nuevas tecnologías parecen estar ligados al sentimiento generalizado que existe en las nuevas generaciones, para quienes la preocupación por el medio ambiente está en primer plano y en consecuencia la perspectiva amazónica ha sido objeto de interés.

En el campo literario, William Ospina ha escrito la saga de sus obras históricas evocando las culturas amazónicas, no solo en Ursúa sino también en su reciente publicación El País de la Canela, que obtuvo el premio Rómulo Gallegos. En la literatura también es definitiva la presencia de La Vorágine, que marca un antecedente decisivo en la visión que se tiene al interior del país sobre la selva y la divulgación de los desmanes que ha causado la explotación del caucho en las comunidades indígenas. 
Sobre el escenario de las selvas colombianas y particularmente sobre el Vaupés, sorprenden los textos que recientemente se han publicado, por los secuestrados de las Fuerzas Armadas Revolucionarias, quienes, al salir de sus vivencias en la selva, han iniciado su catarsis narrando sus crónicas de secuestro en el contexto selvático, contribuyendo en cierta forma a afianzar el imaginario del infierno verde, estigmatizando estos territorios como lugares de desdicha, de violaciones, hambrunas, injusticias y tratamientos en condiciones inhumanas. Estas expresiones y testimonios, que se han lanzado al público nacional e internacional, tienen un gran impacto sobre los imaginarios que se transmiten sobre la selva. Los medios de comunicación están legitimando la frase de que "en la selva se pudre la gente", cuando la situación es diferente, porque lo que pudre a los seres humanos, en el caso del secuestro, son las condiciones forzadas que limitan su libertad y no el entorno selvático donde han sido llevados.

La actualización del infierno verde como zona de acción de grupos al margen de la ley pone en peligro la riqueza cultural, biológica y paisajística de este territorio, porque puede estigmatizar las comunidades que se están organizando, buscando reconocimiento e interlocución directa, en diferentes ámbitos estatales, para luchar por sus derechos y para proteger sus territorios y su existencia. Hay varias organizaciones indígenas que, en asocio con algunas ONG que trabajan en proyectos investigativos y culturales, están organizando dispositivos de interlocución con el Estado y con organizaciones internacionales, que les permitan defender sus derechos. Ahora más que nunca se hace necesario escucharlos y respetarlos para difundir la importancia de sus conocimientos, sus creencias y sus mitos, que han sido adquiridos y decantados a través de miles de años.

Los registros audiovisuales sobre el río Apaporis han sido solo cinco hasta la fecha: Las tomas para cine (en formato super 8) de Thomas van der Hammen, quien acompañó a Richard Evans Schultes en 1952; los registros fotográficos del Inderena sobre el Chiribiquete, también de Thomas van der Hammen; los registros en video del pintor holandés Jean Willem Meurkens; la serie "Travesías" del programa de Audiovisuales, realizada por Alfredo Molano y Constanza Ramírez, y el documental “En busca del Río” del profesor Antonio Dorado Z. 
Notas:

1 El siguiente artículo hace parte del trabajo de Investigación "Aproximaciones al Paisaje y las Bellezas escénicas naturales. Río Apaporis".

2 Profesor Titular de la Escuela de Comunicación Social de la Universidad del Valle.

3 Carlos E. Franky y Carlos G. Zárate, editores. Estudios en la Amazonia colombiana. En: IMANI MUNDO. Universidad Nacional de Colombia, Instituto Amazónico de Investigaciones Imani. Sede Leticia, 2001.

4 DAVIS, Wade. El Río.

5 GARCÍA MÀRQUEZ, Gabriel. La soledad de América Latina. En: Discursos Premios Nobel. P. 133

6 Ídem. P. 134.

7 Tratado de límites y navegación fluvial entre Colombia y los Estados Unidos del Brasil. Iniciado en 1907 y concluido y aprobado en Río de Janeiro en 1928, mediante el cual Colombia quedó reconocido como único país colindante con Brasil, entre los ríos Apaporis y Amazonas.

8 Este comentario no pretende hacer ningún señalamiento positivo o negativo de la obra literaria, simplemente se trata de aclarar el contexto geográfico cultural del Amazonas, recreado en la Vorágine.

9 DAVIS, Wade. The Lost Amazon.

\section{Bibliografía:}

ARCHEM, Kaj et ál. Etnografía Macuna. Tradiciones, relatos y saberes de la Gente de Agua. Bogotá: Instituto Colombiano de Antropología e Historia - ICANH, 2004.

ARDEVOL, Elisenda y PÉREZ TOLON, Luis. Imagen y cultura. Perspectivas del cine etnográfico. Granada : Diputación provincial de Granada, 1995

ARISTÓTELES. Arte poética. Arte retórica. México: Editorial Porrúa, 1999.

AUMONT, Jacques. El ojo interminable. Buenos Aires: Paidós, 1996.

BACHELARD, Gastón. La poética de la ensoñación. México: Fondo de Cultura Económica, 1982.

BATESON, Gregory. Una unidad sagrada. Barcelona: Gedisa, 1993.

BERMÚDEZ, Olga. Visiones de medio ambiente a través de tres etnias colombianas. Bogotá: Instituto de Estudios Ambientales, IDEA, Universidad Nacional - Fondo FEN, 1996.

CAPRA, Fritjof. La trama de la vida. Una nueva perspectiva de los sistemas vivos. Barcelona : Anagrama, quinta edición, 2003.

CÁRDENAS LÓPEZ, Dairon (Ed.). Flora del Escudo Guyanés en Inírida (Guainía, Colombia). Bogotá : Instituto Amazónico de Investigaciones Científicas SINCHI, 2007.

CAYÓN, Luis y TURBAY, Sandra. Discurso chamánico, ordenamiento territorial y áreas protegidas en la Amazonía Colombiana. En : Journal of Latin American Anthropology. Vol. 10 No. 1. Los Angeles: University of California Press, 2005. 
DAVIS, Wade. The lost Amazon. San Francisco, California : Insight Editions, 1994.

-.--.--- El Río. Exploraciones y descubrimientos en la selva amazónica. Bogotá : El Áncora Editores - Fondo de Cultura Económica., 2005.

DUPERLY, Oswaldo. Lo que se Hereda no se Hurta. Memorias. Bogotá: Ediciones Tercer Mundo, 1978.

ESCOBAR, Arturo. El final del salvaje. Naturaleza, cultura y política en la antropología contemporánea. Santafé de Bogotá: Instituto Colombiano de Antropología - CEREC, 1999.

FIORI REGIO, Lavinia y MONSALVE PINO, Juan Cristóbal. El baile del Muñeco. Bogotá: Cooperativa Editorial Magisterio, 1995.

FRANCO, Roberto. Los Carijonas de Chiribiquete. Bogotá: Fundación Puerto Rastrojo y Unión Europea, 2002.

FRANKY, Carlos E. y ZÁRATE, Carlos G., editores. Estudios en la Amazonía colombiana. En: IMANI MUNDO. Universidad Nacional de Colombia, Instituto Amazónico de Investigaciones Imani. Sede Leticia, 2001.

FRIED SCHNITMAN, Dora. Nuevos paradigmas, cultura y subjetividad. Argentina: Paidós SAICF, 1995.

GARCÉS GUERRERO, Diego Miguel et ál. Gran libro de los parques nacionales de Colombia. Santafé de Bogotá : Intermedio Editores, Círculo de Lectores, 1994.

GARCÍA MÀRQUEZ, Gabriel. La soledad de América Latina. En: Discursos Premios Nobel. Bogotá: Común Presencia Editores. Primera edición, 2002.

GUEVARA, Juan V. Etnodesarrollo y medicina indígena ecológica. Mitú: Departamento Administrativo de Salud del Vaupés, 1984.

Plan de atención básica intercultural (PAB). Mitú: Departamento Administrativo de Salud del Vaupés, 2003.

HURTADO GARCÍA, Andrés. Colombia secreta. Bogotá : Villegas Editores, 2005.

INSTITUTO AMAZÓNICO DE INVESTIGACIONES CIENTÍFICAS - SINCHI. Vaupés. Entre la colonización y las fronteras. Bogotá, 2006.

KAPUSCINSKY, Ryszard . Encuentro con el otro. Barcelona : Editorial Anagrama, 2007.

KESSLER, Mathieu. El paisaje y su sombra. Idea universitaria, 2000.

LOVELOCK, James. Homenaje a Gaia. Pamplona : Oxford University Press - Universidad de Navarra - Editorial Laetoli, S.L. 2005.

MADERUELO, Javier. El paisaje. Génesis de un concepto. Madrid : Abada editores, 2006.

MAY, Georges. La autobiografía. México : Fondo de Cultura Económica, 1982

MILANI, Rafaelle. El arte del paisaje. Madrid : Editorial Biblioteca Nueva, 2007. 
MOLANO, Alfredo y RAMÍREZ, María Constanza. Apaporis. Viaje a la última selva. Bogotá : Editorial Planeta, 2002.

MORCOTE RíOS et ál. Pueblos y paisajes antiguos de la selva amazónica. Universidad Nacional de Colombia, Taraxacum Washington, D.C. y Smithsonian Institut, Washington D.C., Bogotá, 2006.

NICHOLS, Bill. La representación de la realidad. Barcelona : Paidós, 1997.

PALACIO, Germán et ál. Amazonía desde dentro. Aportes a la Investigación de la Amazonía Colombiana. Imani Mundo II. Bogotá : Universidad Nacional de Colombia sede Amazonía, Saber y Gestión Ambiental e Instituto Amazónico de Investigaciones IMANI, 2007.

PÉREZ CORREA, Marleny y BORRERO WANANA, Milciades. Mari Jiti Kiti. Vaupés. Mito y realidad. Bogotá : Ediciones desde abajo, 2004.

POPESCU, Petru. El Amazonas nace en el cielo. Bogotá : Editorial Norma, 1993.

RIVERA, José Eustasio. La vorágine. Santafé de Bogotá : Panamericana Editorial, 2000.

RIVERA OSPINA, David. La Orinoquía de Colombia. Santiago de Cali : Banco de Occidente, 2005.

ROHMER, El gusto por la belleza. Barcelona : Paidós, 2000.

SCHULTES, Richard Evans y RAFFAUF, Robert F. El bejuco del alma. Los médicos tradicionales de la Amazonía colombiana, sus plantas y sus rituales. Bogotá : El Áncora Editores y Fondo de Cultura Económica. 2004.

SULLÁ, Enric. Teoría de la novela. Antología de textos del siglo XX. Barcelona : Grijalbo Mondadori, 1996.

TAGG, John. El peso de la representación. Barcelona : Gustavo Gili, 2005.

TRUFFAUT, François. El placer de la mirada. Barcelona : Paidós, 1999.

VAN DER HAMMEN, María Clara. El manejo del mundo. Estudios en la Amazonía Colombiana. Tomo IV. Bogotá : Fundación Tropenvos, 1992.

VON HILDEBRAND, Patricio. Parque Nacional Natural Chiribiquete. Fundación Puerto Rastrojo. Bogotá, 1999.

VON HILDEBRAND, Martín y REICHEL, Elizabeth. Introducción a la Colombia Amerindia. Instituto Colombiano de Antropología.

http://www.lablaa.org/blaavirtual/antropologia/amerindi/miripara.htm 